\title{
Arquitetura e espaços da cultura escolar: o Ginásio Estadual de Santo Antônio da Platina- PR (1953)
}

\author{
Architecture and spaces of school culture: \\ the State Gymnasium of Santo Antônio da Platina-PR (1953)
}

\author{
Lucas Batista HERNANDES' \\ Tony HONORATO2
}

\begin{abstract}
Resumo
O Ginásio Estadual de Santo Antônio da Platina, localizado no Paraná, foi criado por lei em 1945 e funcionou em um prédio improvisado até 1953 . Assim, objetiva-se apresentar e analisar a solução arquitetônica e a distribuição dos espaços interno do edifício do Ginásio inaugurado em 1953. É uma pesquisa com base na historiografia da educação que discute arquitetura e espaços escolares. Têm-se as plantas estruturais do prédio como fonte histórica central. Como resultado, percebe-se um edifício-escola representante de um programa arquitetônico fomentador de lugares de aprendizagens, relaçôes de poder e sociabilidades na cultura escolar secundarista vivida em meados do século XX.
\end{abstract}

Palavras-Chave: Ensino Secundário. Arquitetura e Espaço. Cultura Escolar. História da Educação.
Abstract

The State Gymnasium of Santo Antônio da Platina, located in Paraná, was created by law in 1945 and operated in an improvised building until 1953. Thus, it aims to present and analyze the architectural solution and the distribution of the internal spaces of the Gym building inaugurated in 1953. It is a research based on the historiography of education that discusses architecture and school spaces. We have the structural plans of the building as a central historical source. As a result, can be perceived a school-building representative of an architectural program that promotes places of learning, power relations and sociability in the secondary school culture lived in the mid-twentieth century.

Keywords: High school. Architecture and Space. School Culture. History of Education.

1 Possui graduação em História pela Universidade Estadual do Norte do Paraná (2012). Possui graduação em Ciências Sociais pela Universidade metropolitana de Santos (Unimes) 2015. Graduado em Pedagogia pela Universidade Cruzeiro do Sul.(2016). Possui Pós-graduação Lato Sensu Especialização em Docência no Ensino Superior (2013), e em Neuropedagogia (2014), ambas pela Univale: Faculdades Integradas do Vale do Ivaí / ESAP: Instituto de Estudos Avançados e Pós-graduação. Pós graduação Lato Sensu Especialização em ensino de filosofia, Sociologia e Ensino Religioso(2015), pela faculdade Dom Bosco. Mestre em educação pelo Programa de Pós Graduação em Educação da Universidade Estadual de Londrina-UEL. Professor da rede municipal de ensino de Santo Antonio da Platina-PR. Professor temporário de Sociologia da rede estadual de ensino do Paraná. E-mail: lucasbhernandes@gmail.com.

2 Pós-doutor em Educação pela Faculdade de Filosofia e Ciências/FFC da Universidade Estadual Paulista \&quot;Júlio de Mesquita Filho\&quot; (FFC/UNESP, 2015), Doutor em Educação Escolar pela Faculdade de Ciências e Letras/FCLAr da UNESP (2011), Mestre em Educação pela Universidade Metodista de Piracicaba (UNIMEP, 2005) e Graduado em Educação Física pela Faculdade de Ciências e Tecnologias/ FCT da UNESP (2002). Líder do Grupo de Pesquisa Processos Civilizadores e do GEPHEEF - Grupo de Estudos e Pesquisas em História da Educação e da Educação Física (Diretório CNPq). Bolsista Produtividade em Extensão da Fundaçấo Araucária (2015-2016). Pesquisador do Projeto Rede CEDESPR. Atualmente é Professor Associado AC-A da Universidade Estadual de Londrina/UEL, atuando na Graduação e no Programa de Pós-Graduação em Educação (PPEdu - Linha de Pesquisa: Perspectivas Filosóficas, Históricas, Políticas e Culturais da Educação). E-mail: tony@uel.br.

R. Educ. Públ.

Cuiabá

v. 28

n. 69

p. $741-763$

set./dez. 2019 


\section{Introdução}

A escola enquanto um lugar específico pensado, projetado, construído e utilizado para fins de ensino formalizado, destinado à formação de gerações, foi e é uma problemática na realidade educacional brasileira. Essa problemática, desde o início do século XIX com o ensino mútuo nas escolas elementares (BASTOS; FARIA FILHO, 1999), vem sendo enfaticamente apresentada e reelaborada com o passar do tempo em situaçóes de diferentes níveis de escolarização (SOUZA, 1998; MONARCHA, 1999a; DALLABRIDA, 2001; BENCOSTTA, 2005). Os níveis de ensino exigem diferentes projetos arquitetônicos e espaços para experiência dos sujeitos numa cultura escolar. Embora, ao longo da história da educação brasileira muitas alternativas de soluçôes arquitetônicas foram propostas e implementadas no país, algumas mais cedo, outras mais tardiamente, no século XXI prossegue-se em busca de um modelo de escola com um lugar específico de promoção de práticas e saberes educativos.

Essa realidade provoca pensar como vem se dando ao longo da história educacional brasileira a construção de edifícios-escola como soluçóes arquitetônicas fomentadoras de culturas escolares. Assim procurou-se escolher, para este texto, uma leitura a partir da história da educação no seu esforço de compreensão da cultura escolar ginasial, conformada em edifício-escola específico. Evitando repetir discussóes já realizadas por pesquisadores sobre a história do ginásio no Brasil e suas dimensóes educativas, objetivou, neste artigo, apresentar e analisar a solução arquitetônica e a distribuição dos espaços interno de um edifício escolar destinado ao ensino secundário praticado em meados do século XX. A pesquisa recaiu sobre uma escola localizada numa cidade do interior do estado do Paraná: o Ginásio Estadual de Santo Antônio da Platina-PR.

O Ginásio foi criado pelo Decreto no 385 de 22 de agosto de 1945. Em 1947, ele começou a funcionar em Santo Antônio da Platina, município localizado no norte do Estado do Paraná, de forma provisória no prédio de outra instituição - o Grupo Escolar "Dr. Ubaldino do Amaral”, onde ocupou lugar até 1953. Entre 1947 e 1953, houve a construção de um prédio próprio para o Ginásio que tinha por finalidade ofertar o nível de ensino secundário de $1^{\circ}$ ciclo $^{3}$, contemplando da $1^{\text {a }}$ a $4^{\text {a }}$ série (HERNANDES, 2019).

3 Segundo as especificaçôes da Lei Orgânica do Ensino Secundário (BRASIL, 1942), o ensino seria ministrado em dois ciclos. O primeiro compreenderia um só curso: o curso ginasial. O segundo compreenderia dois cursos paralelos: o curso clássico e o curso científico. 
Para a realização da pesquisa foram consultados os acervos do antigo Ginásio ${ }^{4}$, abrigados no atual Colégio Estadual "Rio Branco". Entre os documentos encontrados, privilegiou-se como fonte histórica principal as plantas estruturais arquitetônicas do edifício do Ginásio, entendidas não como propostas de estruturas físicas estáticas, mas como uma dimensão visual do edifício e seus espaços onde relações entre os sujeitos seriam/foram estabelecidas. As legislações, relatórios de governo, fotografias e bibliografias foram consideradas fontes complementares. Para desenvolvimento da análise fez-se o uso da historiografia da educação que discute arquitetura e espaços de culturas escolares, principalmente a abordagem elaborada por Antonio Viñao Frago e Agustín Escolano (2001), em Currículo, espaço e subjetividade: a arquitetura como programa.

De acordo com Viñao Frago (1995, 2001), a escola, enquanto instituição, representa um espaço que está disponível e disposto para transformar-se em lugar construído socialmente.

A aceitação da necessidade de um espaço e de um edifício próprios, especialmente escolhidos e construídos para ser uma escola, foi historicamente o resultado da confluência de diversas forças ou tendências. Algumas mais amplas, de caráter social, como a especialização ou segmentação das diversas tarefas ou funçôes sociais e a autonomia das mesmas, uma em relação às demais. E outras mais específicas em relação ao âmbito educativo [...] (FRAGO, 2001, p. 73).

A instituição escolar por meio de seu edifício deve ser identificada arquitetonicamente como tal, porque ela é singular e adquiriu historicamente uma certa autonomia em relação a outros estabelecimentos e poderes. No conjunto das próprias instituições escolares, há diferenças arquitetônicas entre elas em razão das especificidades educativas exigidas em diferentes espaços formativos. $\mathrm{O}$ que permite falar de culturas escolares no plural, segundo Viñao Frago (1995).

4 "Desde a sua criação, em 1945, a instituição passou por inúmeras transformaçôes no âmbito da oferta de cursos, sendo que entre as principais estão: 1952: criação do primeiro curso normal; 1955: transformado em estabelecimento de ensino secundário de 2o Ciclo; 1974: implantação do ensino de 20 Grau; 1977: funcionamento do ensino de $1^{\circ}$ e $2^{\circ}$ Graus; 1981: funcionamento do curso de formação de professores para o magistério pré-escolar, em nível de 2o Grau; 1983: implantação do curso propedêutico; 1999: implantação gradativa do ensino médio; 2003: aprovado o curso de técnico em informática - subsequente e integrado" (HERNANDES, 2019, p. 15). Atualmente o estabelecimento de ensino é denominado Colégio Estadual "Rio Branco" - CERB. 
Escolano (2001) considera que a arquitetura escolar, como forma de escritura do espaço, expressa e institui um discurso e potencializa práticas de experiências decisivas na aprendizagem das estruturas corporais dos sujeitos.

A arquitetura escolar é também por si mesma um programa, uma espécie de discurso que institui na sua materialidade um sistema de valores, como os de ordem, disciplina e vigilância, marcos para a aprendizagem sensorial e motora e toda uma semiologia que cobre diferentes símbolos estéticos, culturais e também ideológicos. (ESCOLANO, 2001, p. 26).

A questáo da arquitetura, da distribuição dos espaços e seus usos são elementos constitutivos das culturas escolares (VIÑAO FRAGO, 1995; FARIA FILHO; VIDAL, 2000; VINAAO FRAGO; ESCOLANO, 2001; MAGALHÁES, 2004; BENCOSTTA, 2005; FARIA FILHO et al., 2004). Esses elementos analíticos da dinâmica escolar, segundo Faria Filho et al. (2004), embora recentes na escrita da história da educação no Brasil, têm-se tornado cada vez mais frequentes com a emergência dos estudos sobre culturas escolares, pois provocam compreensóes de uma escola não estática e em íntima relação com as representaçôes e práticas dos sujeitos na ocupação e apropriação a respeito das dimensóes espaciais estruturantes da vida escolar.

Ao prefaciar o livro História da educação, arquitetura e espaço escolar, organizado por Bencostta (2005), Rosa de Fátima Souza considera que:

Portadores de significados múltiplos, a arquitetura e o espaço escolar têm-se se constituído nos últimos anos em promissoras vertentes de investigação sobre a cultura escolar. Estudos dessa natureza tendem a surpreender até mesmo o pesquisador que almejando encontrar o inusitado e o extraordinário, ao se voltar para o interior da escola, para as práticas e o cotidiano, depara-se com o prosaico, os lugares-comuns, com aqueles aspectos quase sempre negligenciados por comporem a estrutura habitual de nossa percepção sobre a realidade. (SOUZA, 2005, p. 08).

O estudo da arquitetura e dos espaços das culturas escolares lança, a partir daquilo que estava dado como natural e imperceptível no cotidiano, possibilidades de interpretaçôes sobre as relaçóes de sociabilidades, de aprendizagem e de poder na experiência escolar e, ao mesmo, tempo busca relaçóes sociais e políticas mais amplas.

Desse modo, atentando-se para as questóes inerentes à historiografia da educaçáo sobre arquitetura e espaços escolares, buscou-se aqui produzir uma 
narrativa, a partir das plantas arquitetônicas, sobre o Ginásio Estadual de Santo Antônio da Platina-PR. Como resultado, tem-se a construçáo de um edifícioescola e a distribuição de seus espaços interno ocupados pelos sujeitos, enquanto uma realidade da cultura do ensino secundarista em meados do século XX.

\section{Um prédio para o Ginásio de Santo Antônio da Platina}

No documento oficial do Estado do Paraná denominado Concretização do plano de obras do governador Moyses Lupion (1947-1950), registram-se dados das obras do governo referentes aos edifícios públicos descritos em duas categorias: planejados ou em construção. Nele há informações sobre construções no município de Santo Antônio da Platina-PR, constando dados da obra do prédio do Ginásio (Tabela 1).

Tabela 1- Especificações das obras do Governo Estadual no município de Santo Antônio da Platina-PR.

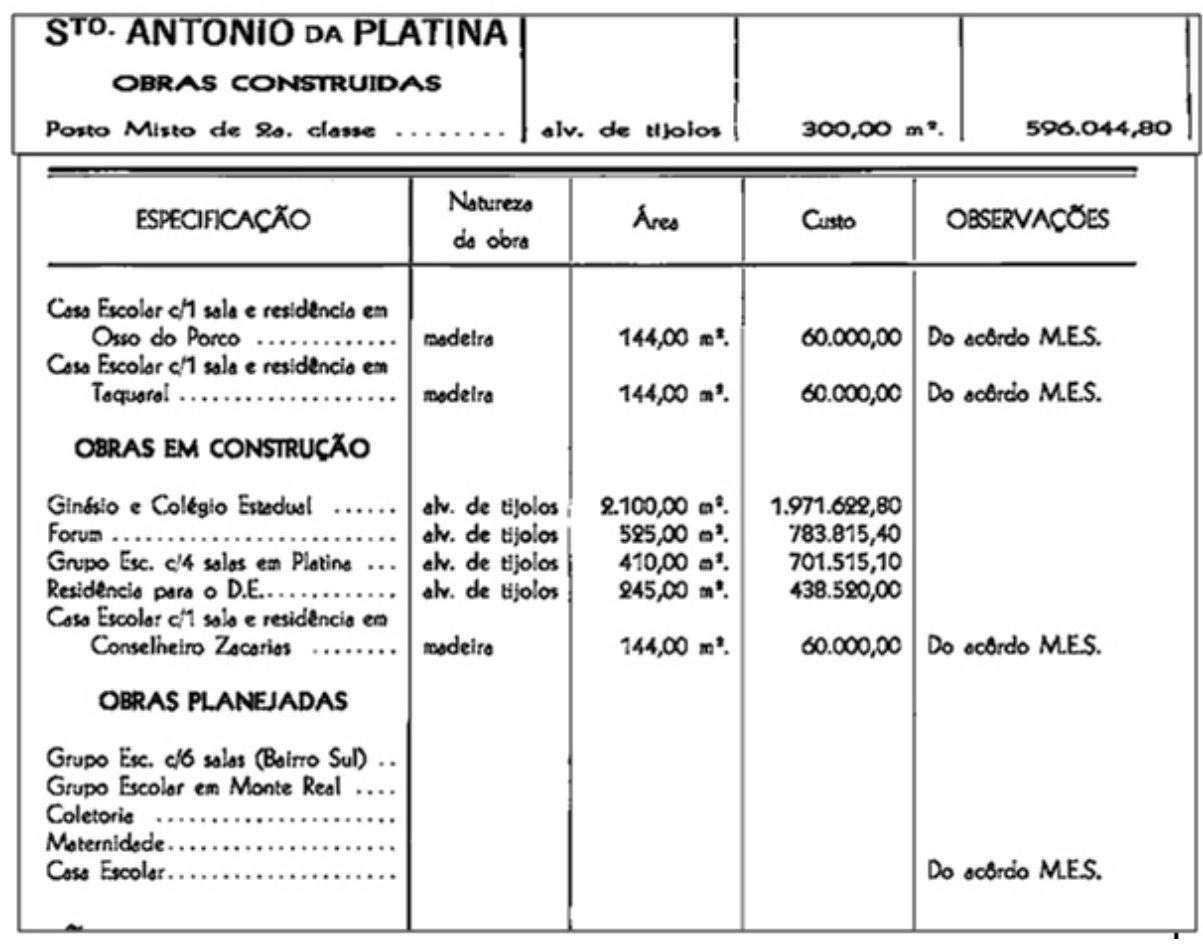

Fonte: (PARANÁ, 1950b, p. 79-80). 
As obras do Ginásio estavam em andamento. A construção do edifício-escola era de alvenaria de tijolos, com área de $2.100,00 \mathrm{~m}^{2}$, com o custo estimado de Cr\$1.971,622,80. Em outro documento, com o título de Mensagem destinada à Assembleia Legislativa do Estado do Paraná do ano de 1950, assinado pelo governador Moyses Lupion, tem-se a descrição da construção do prédio, de uma maneira mais detalhada:

Obra de alvenaria de tijolos, com dois pavimentos, doze salas de aula, diretoria e secretaria, gabinetes médicos e dentário, salas para professores, museu, cantina, biblioteca, auditório e vários grupos de instalaçóes sanitárias, estando na altura da primeira Lage, a qual já está sendo armada. (PARANA, 1950a, p. 206).

Para a construção do prédio do Ginásio, o modelo eleito foi um edifício com dois pavimentos com salas de aula, salas administrativas, gabinete de saúde e demais espaços destinados para a aprendizagem e às atividades escolares cotidianas. No próximo tópico a distribuição do espaço será detalhada.

Segundo Magalhães (2004), para uma interpretação da estrutura, da construçáo de edifícios e dos espaços escolares, devem ser levados em conta fatores como localização, projeçáo e plano arquitetônico, processos de licenciamento, enquadramento paisagístico e urbanístico, tipo de construção, organização dos espaços, estado de conservação, além de adaptaçóes arquitetônicas e espaciais. Para Bencostta (2001), no estado do Paraná, desde o início do século XX, os governantes entendiam o espaço urbano como uma dimensão privilegiada de poder, assim, geralmente, a localização dos prédios escolares deveria funcionar como ponto de destaque na cena urbana, de modo que se tornasse visível, enquanto signo de ideais de determinado governo.

No caso de Santo Antônio da Platina-PR, uma construção de dois pavimentos localizada em uma parte central da cidade, se mostra imponente, representando não só a presença do Estado como um símbolo de poder, educação e prestígio, mas também marcando o imaginário local na intersecção com as culturas escolares que mudam a fisionomia urbana em plena força da economia da cafeicultura dos anos de $1940 \mathrm{e}$ 1950. A construção ocupou um terreno de um quarteirão da região central da cidade.

O prédio próprio para o Ginásio fora construído, estando localizado na Rua 19 de Dezembro, número 1.001, na área central do município, e a sua inauguração aconteceu em 1953. As atividades escolares do estabelecimento foram transferidas do prédio do Grupo Escolar "Dr. Ubaldino do Amaral” para o novo prédio (Imagem 1). 
Imagem 1- Prédio do Ginásio Estadual de Santo Antônio da Platina, 1953

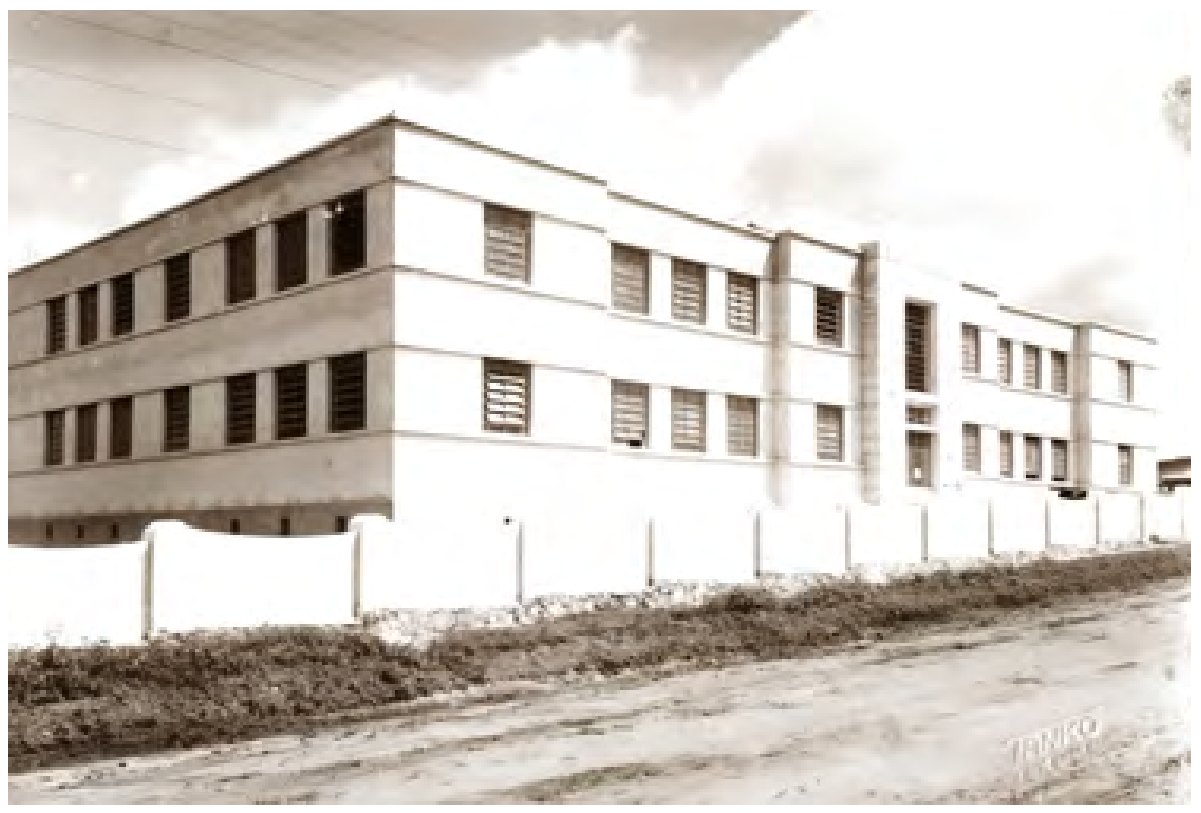

Fonte: Arquivo do Colégio Estadual "Rio Branco". Autoria da foto: José Nicolau Tanko.

\section{Modelo de arquitetura e a distribuição dos espaços do Ginásio}

As plantas estruturais do prédio servem de fontes históricas, particularmente, porque revelam a distribuição temática dos espaços e os modos de vida escolar. O prédio foi construído considerando uma arquitetura em formato de " $\mathrm{M}$ ", com dois pavimentos (térreo e superior), poráo e anexos. Tal formato remete a um modelo que na relação escola e comunidade externa valoriza a contemplação da sua fachada (Imagem 1) e oculta o seu interior. Isso, conforme Viñao Frago (2001), trata-se de um jogo de relaçóes entre o interno e o externo, uma dialética do dentro-fora presente na arquitetura e na vida escolar.

Conforme Correia (2004), esses prédios resultaram de projetos com plantas e fachadas padronizadas, foram construídos em diversos bairros de Curitiba (capital do Paraná), como também em muitas cidades no interior do Estado.

[...] as escolas de dois andares localizavam-se nos bairros mais povoados de Curitiba. Observa-se que suas edificaçóes, normalmente simétricas, constituíam-se por um programa arquitetônico que previa, basicamente, doze salas de aula, com 
a planta em forma de M. A fachada segue a mesma tendência dos prédios térreos, com elementos da arquitetura neocolonial e ainda de maneira bastante simplificada. A entrada principal tem os mesmos detalhes das plantas térreas, com arcadas rebaixadas e um grande arco, de acesso. Ainda na fachada, no segundo pavimento, há a construção de janelas balcão e saída por apenas uma porta, lembrando ainda mais as características das casas residenciais. (CORREIA, 2004, p. 8).

No Estado do Paraná, para construçóes de escolas foram utilizadas plantas com projetos de interiores e fachadas padróes, obedecendo um determinado modelo de arquitetura. A solução arquitetônica do Ginásio Estadual de Santo Antônio da Platina sinalizava uma política estadual de época.

Imagem 2- Planta do pavimento térreo (1948)

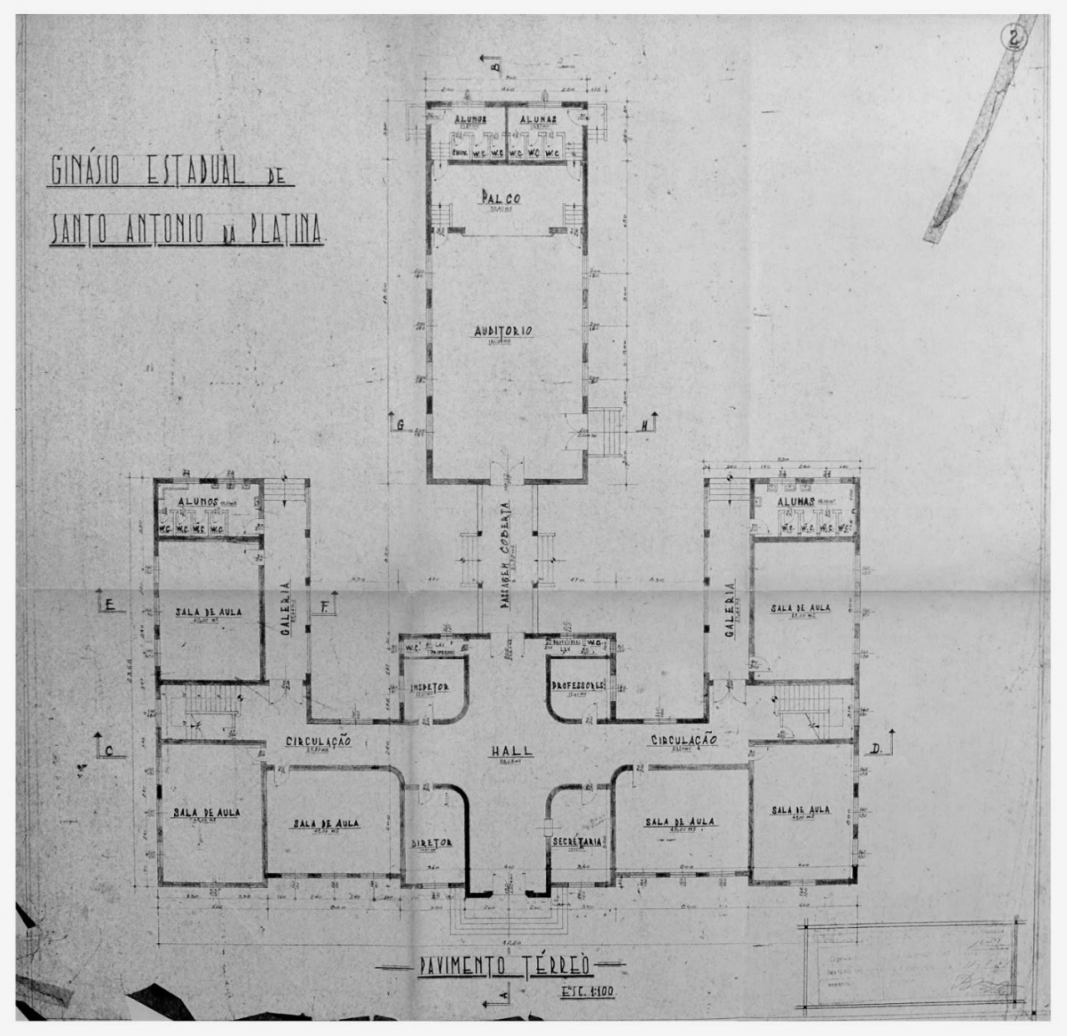

Fonte: Arquivo do Colégio Estadual "Rio Branco". 
$\mathrm{Na}$ Imagem 2, visualiza-se a porta principal e o hall de entrada dando acesso às demais repartiçóes do estabelecimento. As salas da parte administrativa, do corpo docente e da direção da instituição se localizam na parte térrea. À direita do hall, na primeira sala, encontra-se a secretaria e à sua frente, do mesmo lado, está a sala dos professores. À esquerda do hall, o primeiro espaço é reservado ao gabinete da direção e à frente a sala dos inspetores. Constata-se que as seçóes administrativas pedagógicas estavam próximas umas das outras, que permitem dimensionar a existência de integração espacial entre professores, funcionários da secretaria, inspetores e direção. A proximidade entre as salas facilitaria a comunicação e interação entre os sujeitos do administrativo pedagógico. Destaca-se que as salas do administrativo pedagógico ocupavam o centro do prédio, formando um quadrado de poder para comandar as atividades escolares.

O quadrado administrativo pedagógico representa um lugar de poder e prestígio acadêmico, com destaque para o gabinete da direção presente já na entrada principal do edifício. Um gabinete de diretor, segundo Viñao Frago (2005), representa o papel e as funções desse agente, principalmente quando o seu espaço tem centralidade no prédio de uma instituição, o que facilitaria suas funçóes como vigiar professores, orientar o administrativo, intervir nas aulas, entre outras. Ocupando lugar de destaque a partir de seu gabinete, o papel de um diretor ganha outra concepção ao passo que se torna o representante máximo da instituição perante à comunidade, sendo o responsável pelos trabalhos administrativos gerais e pedagógicos.

No caso do Ginásio de Santo Antônio da Platina, a sala da direção se localizava próxima a entrada principal do estabelecimento, por onde era o acesso dos membros da comunidade interna e externa à instituição. Tratava-se de localização estratégica para se estabelecer relaçóes interpessoais, conduzindo processos na condição de autoridade detentora de maiores gradientes de poder. O diretor é o maior representante administrativo dos interesses do Estado em uma instituição escolar, o que lhe coloca como sujeito condutor das políticas educacionais e mediador das relaçóes com os membros da sociedade em geral.

Ainda no hall de entrada, têm-se os corredores laterais e um central de circulaçáo ligando o quadro administrativo pedagógico às salas de aula e ao auditório/saláo nobre. Os corredores eram espaços de passagens dos alunos, professores e demais sujeitos. Destaca-se que na arquitetura dos espaços, analisada pelas plantas estruturais, predomina-se o retilíneo favorecendo a visibilidade e a prática de dispositivos de controle e de vigilância dos comportamentos dos sujeitos da escola.

No Ginásio, o auditório era constituído de palco de apresentaçóes/debates, de cadeiras para plateia e de banheiros. 


\section{Imagem 3- Salão Nobre do Ginásio Estadual década de 1950}

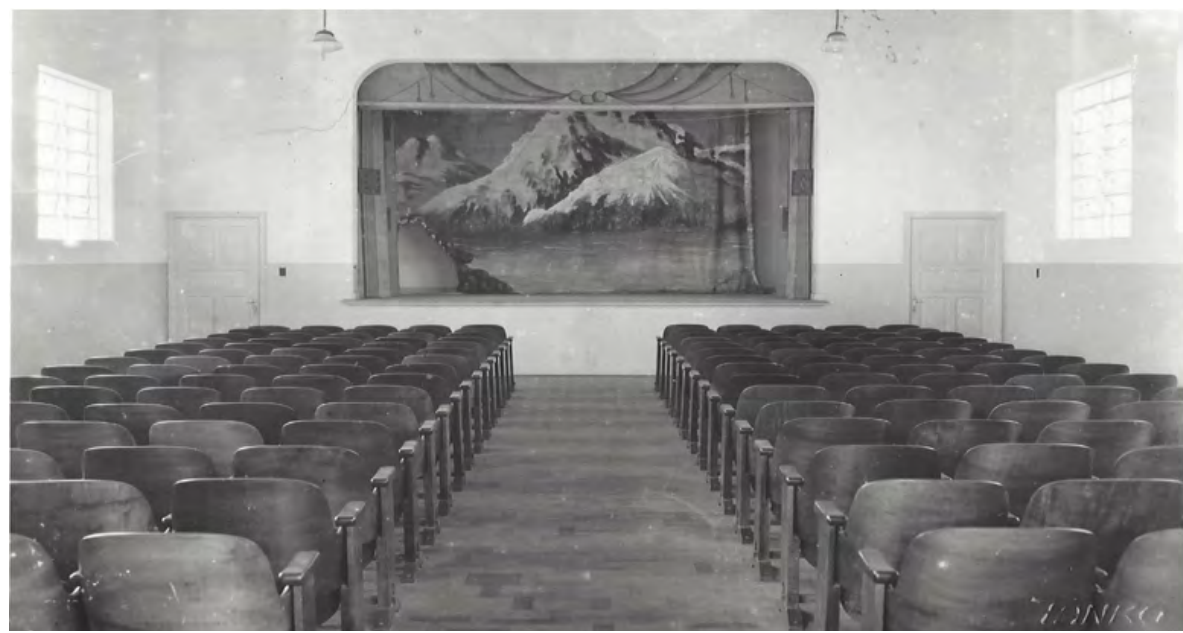

Fonte: Arquivo do Colégio Estadual "Rio Branco". Autoria da foto: José Nicolau Tanko.

No prédio escolar, o auditório tinha várias funções:

O auditório implantado nos edifícios de dois pavimentos, podia ser avistado logo na porta de entrada. Era o único local coberto e provavelmente as aulas de Educaçáo Física eram realizadas naquele espaço nos dias de chuva. Além disso, era destinado às solenidades cívicas, às festas escolares ou mesmo às reunióes de pais. Esse equipamento poderia parecer exagerado, se fossem consideradas apenas as necessidades escolares, mas as escolas começavam a preocupar-se com atividades sociais, oferecendo espaços a ser utilizados principalmente por adultos e pelos pais dos alunos. (CORREIA, 2004, p. 9).

Os espaços escolares abrigavam não somente o corpo escolar como um todo, mas também se mostravam como lugares socioculturais onde se desenvolveriam relaçóes entre os sujeitos da escola e a sociedade. Nesse sentido, o auditório era um espaço estratégico para estabelecer e apresentar elementos da cultura escolar, bem como um espaço para estabelecer relaçóes com a comunidade externa representada por diferentes setores da sociedade. No auditório do Ginásio, eram comuns reunióes de pais e mestres de alunos e de autoridades locais, bem como apresentaçôes e exposiçóes praticadas pelos alunos a partir das produçóes oriundas das disciplinas escolares. 
Ainda no térreo (Imagem 2), tem-se a distribuição de seis salas de aula, três delas na ala direita e três na ala esquerda. Observa-se que os banheiros para uso dos alunos estão divididos por sexo, entre meninos e meninas, estando localizados nas extremidades das alas, longe um do outro, o dos meninos à esquerda e o das meninas à direita. $\mathrm{O}$ que indica uma preocupação de se evitar contatos entre meninos e meninas durante as saídas para o uso dos banheiros, resguardando a intimidade dos mesmos, sendo também uma forma moral de controlar os comportamentos.

O documento denominado Capacidade do Estabelecimento de 1961 (PARANÁ, 1961) contém informaçóes sobre as salas de aulas do Ginásio que teriam dimensão de 6,00 x 8,00 metros, sendo cada uma com área de $48 \mathrm{~m}^{2}$ previstos. Havia previsão de capacidade de 40 alunos por sala.

As salas de aulas tradicionais eram equipadas com um quadro-negro, logo à frente se encontravam a mesa e cadeira do professor. Este ficaria na parte frontal da sala, bem ao centro, onde era visto por todos e poderia ter o contato visual com a maioria dos estudantes. A disposição da mesa do professor simboliza a presença de uma autoridade de poder pedagógico e detentora do conhecimento.

\section{Imagem 4- Sala de aula do Ginásio Estadual (196-)}

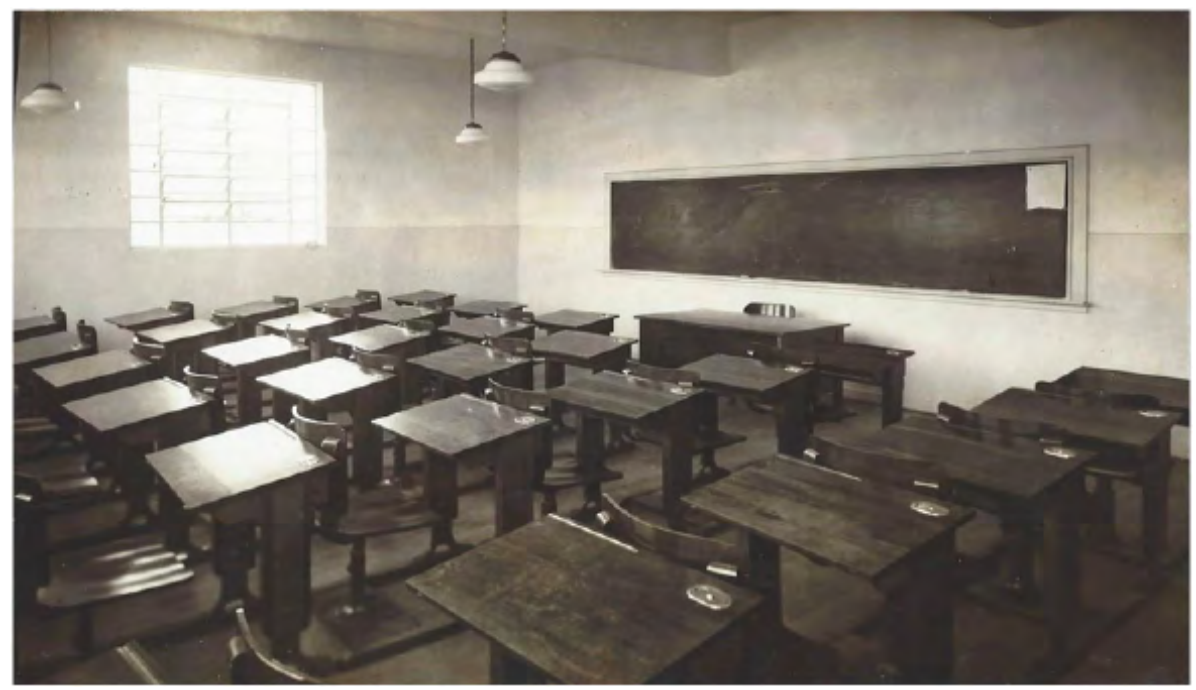

Fonte: Arquivo do Colégio Estadual "Rio Branco". Autoria da foto: não identificada.

As carteiras eram fixadas em uma estrutura no chão, reduzindo a possibilidade de o estudante virar ou mesmo olhar para trás para se comunicar com o colega. $\mathrm{O}$ que indicia a previsão de disciplina e ordem dos comportamentos dos alunos 
na sala de aula, a partir do princípio de que a cultura material educa ${ }^{5}$. Durante as aulas, a atenção do aluno deveria estar voltada ao professor, ao seu material de estudos e à atividade prescrita. Entre as colunas de carteiras, havia um corredor para que o docente circulasse pela sala e acompanhasse o desempenho dos alunos.

Durante a aula, o professor exercia seu controle vigiando os alunos e alunas; sentado ou circulando pelas carteiras, fiscalizava o andamento da aula, das atividades ou avaliaçóes. Quando o professor ou outra pessoa adulta entrava na sala, os alunos deveriam se levantar educadamente e se sentar quando permitido. Esse gesto era um sinal de respeito e punido caso qualquer aluno ou aluna náo o realizasse ou o fizesse com barulho. Portanto, nesse sistema de ensino, o professor era visto como autoridade e depositário do saber, a fonte que os alunos deveriam buscar e com a qual se assemelhar. (MARTINS, 2009, p. 61).

$\mathrm{Na}$ sala de aula (Imagem 4), a iluminação era irradiada por luminárias penduradas no teto, como também contava com a iluminação natural externa provinda das janelas laterais que auxiliavam na circulação de ar. As funçóes das luminárias e janelas indicam que a arquitetura escolar não é uma questão menor para a política higienista defensora de espaços arejados, limpos e promotores da visibilidade. Ar e luz são elementos fundamentais na higienização dos costumes (ROCHA, 2003).

No Ginásio, para cada sala de aula foi atribuído um nome homenageando personagens da história do Brasil, como é caso da sala "Dom Pedro II", "Rocha Pombo", "Joaquim Nabuco", "Duque de Caxias", "Machado de Assis", "Rui Barbosa", "José de Alencar", "Jose Bonifácio", "Júlia Wanderley"6, "Pedro Calmon". O nome do homenageado fica acima do umbral da porta identificando cada sala. O que mostra um intuito de preservar e transmitir valores culturais representados por esses personagens, edificando, nos termos de Nora (1993), um lugar de memória.

5 Para uma interpretação de como a materialidade educa, segundo a visão de professores, conferir: Kincheski; Gaspar da Silva e Valle (2017).

6 Júlia Augusta de Souza Wanderley (1874-1918) foi uma educadora brasileira, um ícone da feminização do magistério no Estado do Paraná (ver: ARAUJO, 2013). 
Imagem 5- Planta do pavimento superior

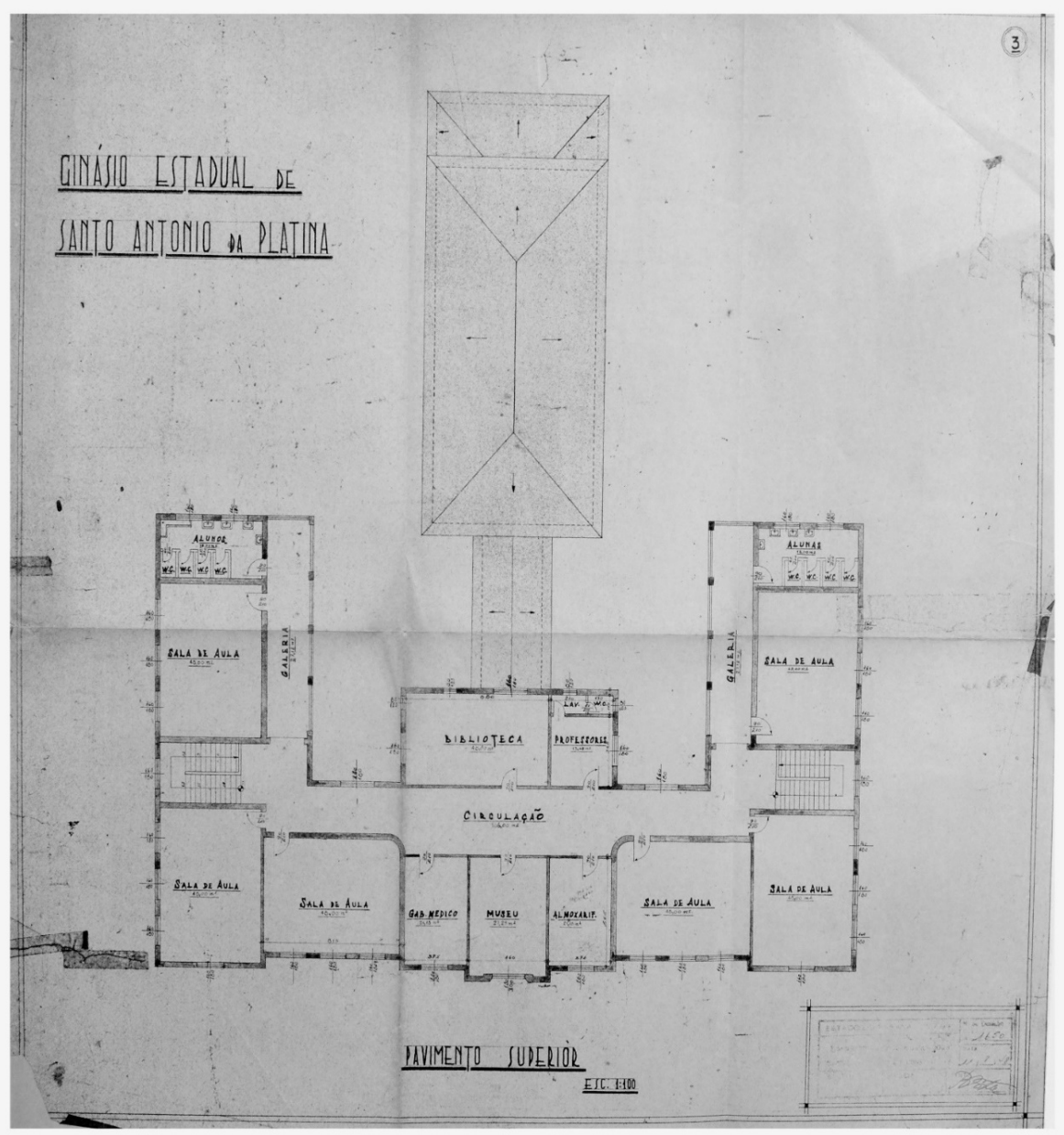

Fonte: Arquivo do Colégio Estadual "Rio Branco".

Na planta do pavimento superior, tanto na ala direita quanto na ala esquerda, têm-se escadarias para acesso do térreo ao piso superior. Este pavimento também foi construído com seis salas de aula, sendo três salas em cada ala do andar, e nas suas extremidades estavam situados os banheiros - feminino de um lado, de outro o masculino. $\mathrm{O}$ museu está localizado bem ao centro do piso superior e na fachada frontal, à sua direita há o almoxarifado e à sua esquerda há o gabinete médico. A biblioteca está disposta em frente ao museu, e ao seu lado, havia uma outra sala de professores. 
Esses espaços caracterizam-se como de intervenção pedagógica, de leitura, de exames de saúde, de presença dos professores e de abrigo de coisas da instituição que também acontecia no porão. Além das salas de aula, no espaço do museu, gabinete médico e biblioteca haveria, diferentemente do quadrado administrativo pedagógico do piso inferior, maior frequência dos alunos, porque eram lugares que faziam sentido mediante ao atendimento dos ginasiais.

Imagem 6- Biblioteca do Ginásio Estadual (1953)

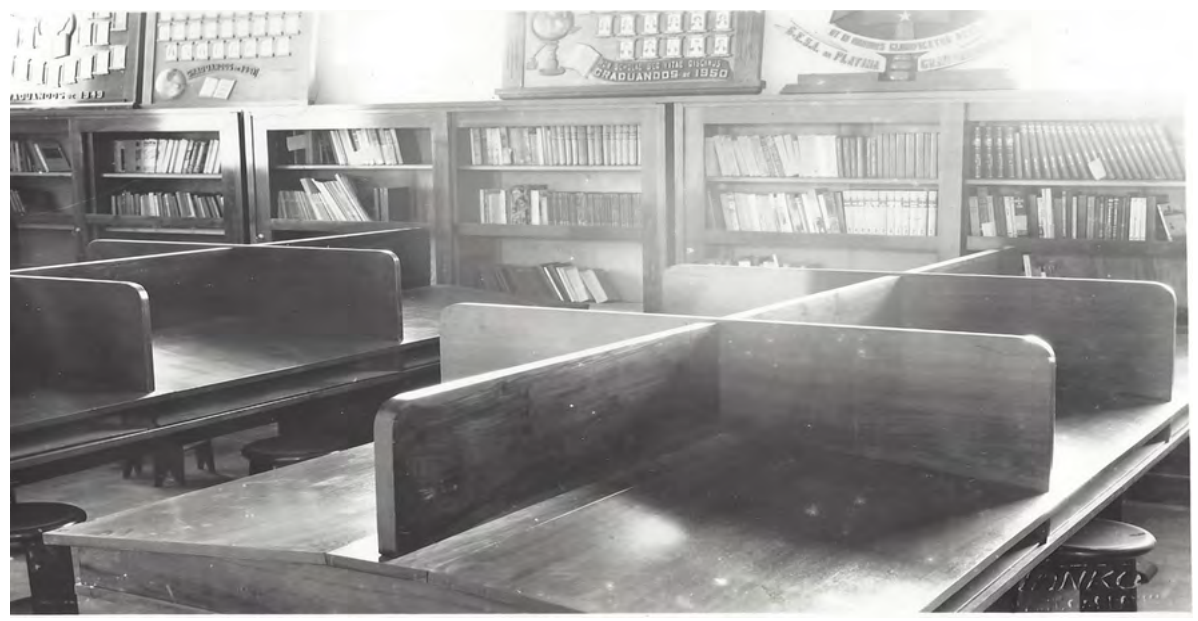

Fonte: Arquivo do Colégio Estadual "Rio Branco". Autoria da foto: José Nicolau Tanko.

Na biblioteca do Ginásio (Imagem 6) havia bancadas de leitura, estantes com livros, quadros de formandos, entre outros objetos. $\mathrm{O}$ espaço indica possibilidades de relaçóes entre os sujeitos, mediadas pela prática de leitura e de estudo e pelo mobiliário no qual os leitores ficavam dispostos lado a lado e frente a frente.

A biblioteca escolar, assim, pode ser pensada como um lugar da memória onde ocorrem práticas de leitura, de escrita e de interpretaçáo, as quais são produtoras de sentidos, de comportamentos, de hábitos e de formação do leitor em um tempo e um espaço. Nesse território, resultante de açóes institucionais, coletivas e pessoais, os agentes promovem uma série de enunciados, estratégias e táticas, tanto na aquisição e na organizaçáo do acervo quanto no estabelecimento de inter-relaçóes sociais em torno do processo de escolarização. (HONORATO; NERY, 2017, p. 178). 
A biblioteca, enquanto espaço e tempos de inter-relações, compõe a caracterizaçáo de uma cultura escolar. Esta é fomentada por um lugar legítimo de organização, de referência e de socializaçáo da leitura e dos estudos de uma cultura pedagógica vivida por alunos, professores, bibliotecários. A biblioteca e o museu foram lugares específicos na atividade educativa ginasial, representaram o intento de um ensino ativo com práticas pedagógicas ligadas à experiência do conhecer por meio de interaçóes.

Para Vidal (2000), a revalorização da biblioteca e do museu possibilitaria o uso mais dinâmico do espaço escolar por alunos e professores. $\mathrm{O}$ uso da biblioteca acarretaria a aquisição de livros e a leitura das práticas pedagógicas que vinham se estabelecendo no período, uma emergência da nova sociedade que se estabelecia. Do mesmo modo, segundo a autora, o museu no espaço escolar tinha o intuito do acolhimento de práticas pedagógicas das ciências naturais. $\mathrm{O}$ museu e a biblioteca se estabeleciam como lugares de experiências de participação ativa do aluno na interação com os mestres e com o aprendizado para leitura de mundo.

$\mathrm{Na}$ realidade do Estado do Paraná da década de 1940, os espaços de bibliotecas, museus, gabinetes médico e laboratórios passaram a ser cada vez mais valorizados nas propostas de arquitetura dos prédios escolares. Conforme Correia (2006), as plantas de prédios de dois andares aplicadas na sociedade paranaense, como é o caso do Ginásio de Santo Antônio da Platina, representaram soluçóes arquitetônicas, em muitos aspectos, articuladas com os ideais da Escola Nova e de influência de grandes centros como Rio de Janeiro e São Paulo. As soluçóes previam espaços para aprendizagem ativa marcada pelo desenvolvimento de capacidades por meio de atividades de observaçóes, pesquisas, perguntas e trabalhos para construir, pensar e propor soluçóes às situaçóes problemas quer em relaçấo ao conjunto de objetos em um ambiente, quer em situaçóes de sentido social e moral.

A distribuição e os espaços destinados à cada função ou para sujeitos escolares específicos, fazem parte de um pensado modelo escolar objetivado na arquitetura. Para Vinão Frago (2001):

A distribuição interna dos espaços, usos e funçôes requer uma análise geral e permite, por sua vez, análises específicas de cada um dos mesmos. Como tendências gerais pode-se indicar a fragmentação e a diferenciação - um espaço para cada atividade -, o incremento dos espaços exigidos e a crescente regulamentação e normalização da arquitetura e dos edifícios escolares em torno de alguns tipos, critérios e módulos estabelecidos. (VIÑAO FRAGO, 2001, p 111). 
A distribuição interna do Ginásio de Santo Antônio da Platina atendia a concepção de escola ativa vigente na época, no caso, a dos anos de 1940 e 1950 quando o prédio foi construído e inaugurado. O prédio de concepçáo de escola ativa deveria prezar pela funcionalidade, economia e racionalidade.

Para Correia (2004), os projetos de prédios escolares representaram um programa de arquitetura e a distribuiçáo interna potencializaria uma nova forma de organizaçáo dos espaços escolares.

A disposição arquitetônica dos prédios, a distribuição e ordenação dos espaços, a orientação estética, a acessibilidade influenciam o quotidiano educacional, quanto à materialidade e à funcionalidade, mas também afetam as representaçôes e os modos de estar, vivenciar, relacionar-se, referenciar e projetar por parte de todos os membros de uma comunidade educativa. (MAGALHAES, 2004, p. 144).

A arquitetura e distribuição interna dos espaços escolares não se caracterizam como neutros, são em si mesmos uma espécie de discurso que carrega em sua materialidade um sistema de determinados valores como os de disciplina, ordem, vigilância (ESCOLANO, 2001). Assim, há a presença de diferentes símbolos estéticos, culturais e ideológicos.

A arquitetura escolar, para além dessa análise semiológica, pode ser contemplada também como um suporte de outros símbolos acrescidos. O edifício-escola, como se sabe, serviu de estrutura material para colocar o escudo pátrio, a bandeira nacional, as imagens e pensamentos de homens ilustres, os símbolos da região, algumas máximas morais e higiênicas, o campanário e o relógio... Isso expressa toda uma instrumentação da escola a serviço dos ideais nacionais, religiosos e sociomorais. (ESCOLANO, 2001, p. 40).

Um edifício-escola pode representar muito mais que apenas uma estrutura fria de tijolos, ferros, vidros e madeiras que está inserida em um determinado espaço urbano. Pode demonstrar diversas leituras do simbólico, do relacional, das questóes de poder, das ideias pedagógicas, das concepçóes políticas e, sobretudo, do lugar vivido pela trama relacional das pessoas na sociodinâmica da cultura escolar.

Na década de 1960, o Ginásio Estadual de Santo Antônio da Platina, segundo Costa (2001), com o subsídio de verbas recebidas da Secretaria Estadual de Educação do Paraná, construiu mais duas novas salas de aula - uma de Economia 
Doméstica e a outra de Artes Industriais -, ampliou o anfiteatro/salão nobre e construiu um refeitório/cantina. Desse modo surgiam mudanças na fisionomia dos espaços do Ginásio, bem como novas possibilidades de relaçóes entre os sujeitos da cultura escolar.

Imagem 7 - Planta área externa do Ginásio Estadual

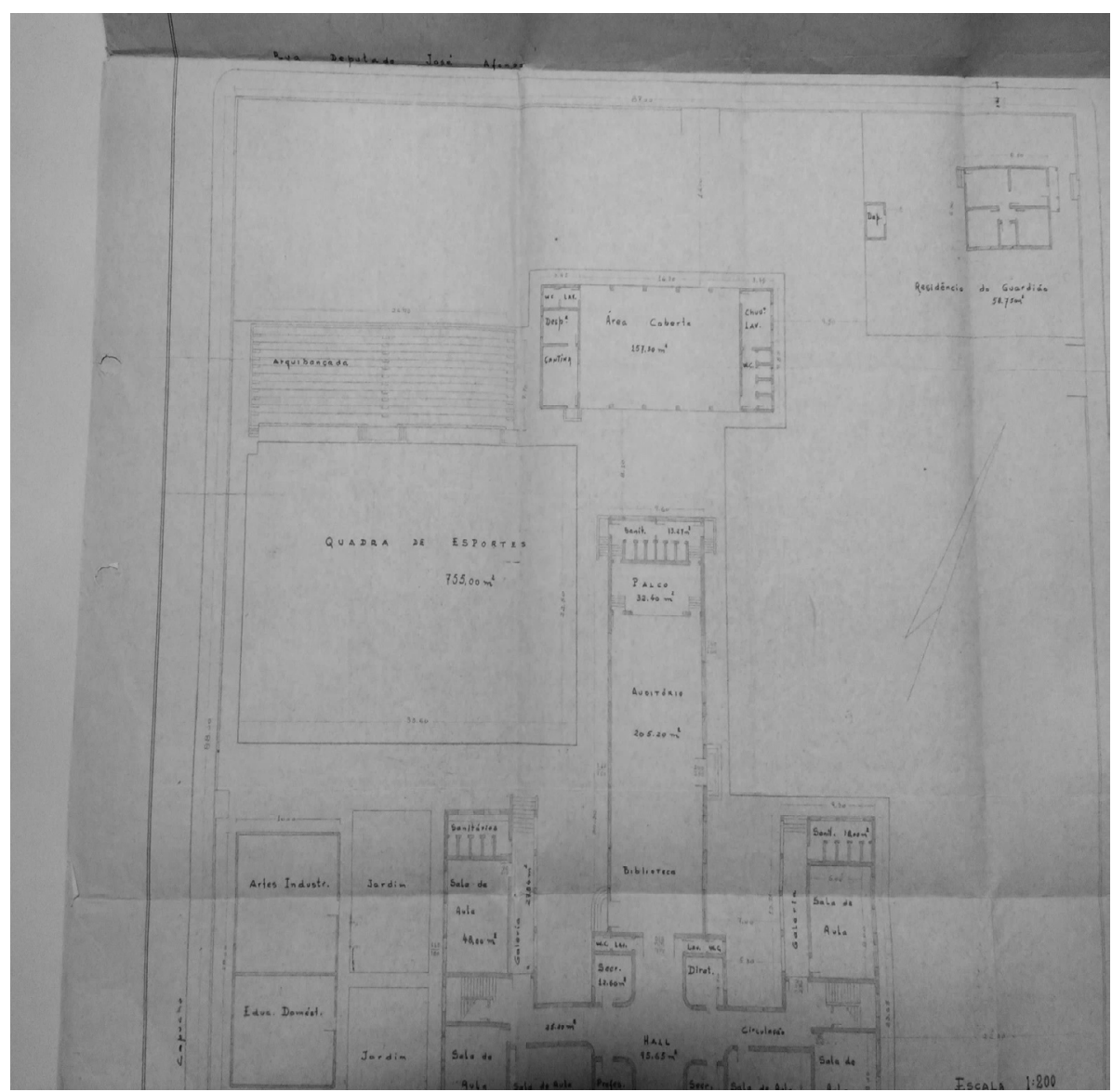

Fonte: Arquivo do Colégio Estadual "Rio Branco".

$\mathrm{Na}$ planta da área externa do Ginásio, identifica-se a proposta de novas construçóes que foram efetivadas nos anos de 1960, agregando então mais elementos arquitetônicos ao edifício inaugurado em 1953. Observa-se, no lado esquerdo da planta (Imagem 7), logo após a proposta de construção do jardim, salas destinadas às aulas de Artes Industriais e de Educação Doméstica. 
Ainda ao lado esquerdo, mais ao fundo, se localizaria a quadra de esportes com sua arquibancada. Próximo à quadra, mais ao centro, construiu-se o refeitório/ cantina. E, à extrema direita da planta, tem-se a proposta de residência do guardião do prédio.

Essa planta nos revela que os novos anexos do prédio tinham importância no funcionamento da cultura escolar do estabelecimento ginasial. Eram espaços fora da centralidade do prédio. Nesses espaços externos, os estudantes teriam aulas de saberes e práticas em salas especiais apropriadas para o desenvolvimento do ensino de Artes Industriais, Economia Doméstica, Trabalhos Manuais, Educação Física/Esportes.

Após cada aula lecionada, os alunos tinham intervalo de 10 minutos até a próxima aula ${ }^{7}$, tempo esse utilizado para se deslocarem, quando necessário, para sala de aulas especiais, irem ao banheiro e/ou mesmo lancharem. Esses intervalos permitiam momentos de interaçáo entre os sujeitos nos espaços, quando podiam conversar e desenvolver relações para além do pedagógico stricto sensu. Entretanto, pelos corredores havia inspetores com poder de vigia de comportamentos dos alunos.

Por sua vez, o refeitório/cantina seria o local para servir refeições aos alunos. Ao lado da cozinha, contava com uma dispensa para guardar alimentos destinados ao preparo das refeiçóes. Existia ainda uma lavanderia e um banheiro, espaços destinados aos funcionários da cantina e zeladoria, àqueles que se encontravam mais distantes da parte administrativa e pedagógica central.

A cantina servia café da manhã antes do início das aulas e almoço entre as aulas do período da manhã e do início da tarde. As refeiçóes eram servidas mediante a organização dos alunos em fila única. Após o recebimento da refeição, os alunos sentavam à mesa que era comprida e rodeada de bancos para que um aluno sentasse ao lado do outro.

A quadra de esportes (Imagem 8) era outro espaço escolar na vida dos ginasiais. Além das práticas curriculares destinadas à disciplina de Educação Física, na quadra eram realizadas práticas de esportes descritas como coletivas e individuais e realizavam ensaios de desfiles e de fanfarras.

\footnotetext{
7 Informaçôes retiradas do documento Grades de horários do Ginásio. Fonte: Arquivo do Colégio "Rio Branco".
} 
Imagem 8- Quadra poliesportiva do Ginásio (196-)

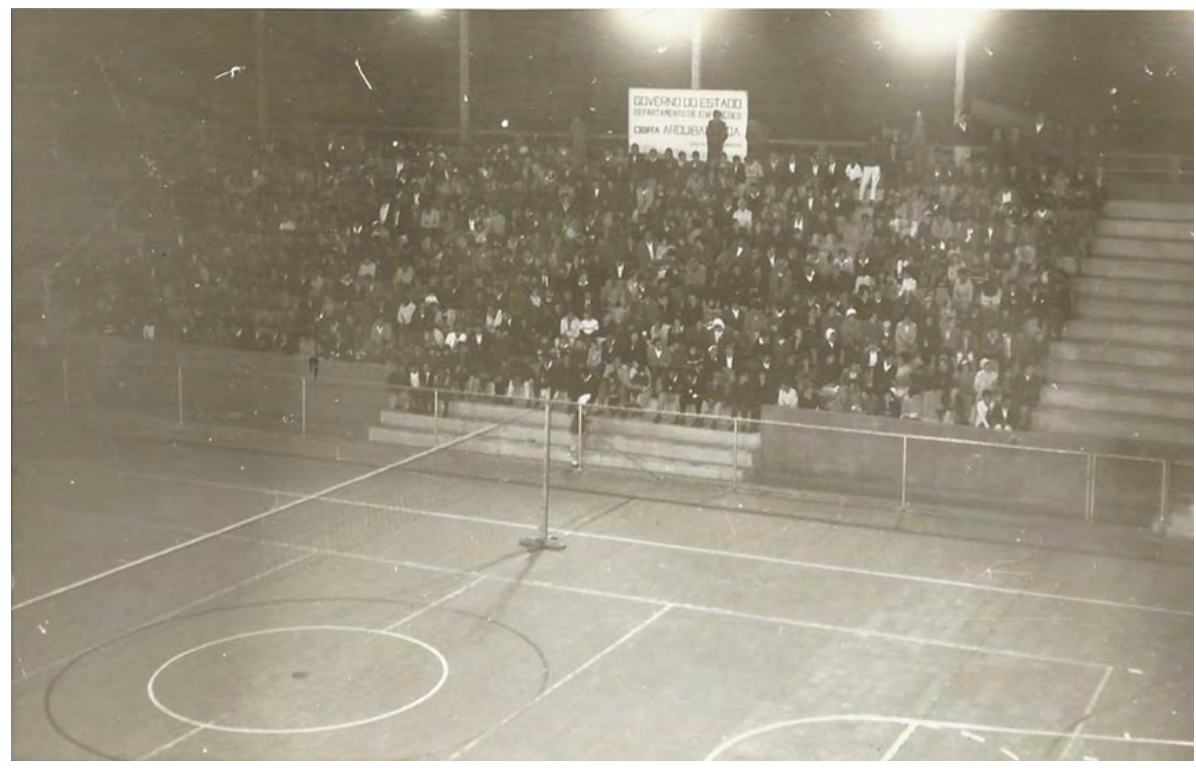

Fonte: Arquivo do Colégio Estadual "Rio Branco". Autoria da foto: não identificada.

A quadra, sem cobertura, ficava ao ar livre. Para evitar exposição dos sujeitos ao sol, as aulas de Educação Física eram realizadas logo de manhã a partir das 6 horas e, depois, no turno vespertino, a partir das 17 horas. Havia uma arquibancada anexa, construída para que as pessoas pudessem assistir as práticas esportivas e de educação do corpo. Além disso, festejos escolares aconteciam na quadra. O espaço tinha funções multiuso e portava refletores de iluminação para atividades noturnas.

$\mathrm{O}$ espaço da quadra também poderia ser usado para a prática de Educação Militar que, segundo o artigo 20 da Lei Orgânica de Ensino Secundário (BRASIL, 1942), seria dada aos alunos do sexo masculino dos estabelecimentos de ensino secundarista, ressalvados os casos de incapacidade física, cuja finalidade era indicar aos menores de dezesseis anos para instrução pré-militar e a instrução militar aos que tivessem completado idade para os serviços militares.

Outro espaço presente na planta, é a residência do guardiáo. Era uma casa localizada na extremidade do terreno da instituição, o seu acesso se dava pelo interior da escola ou por um portão que ligava a casa à rua. A residência do guardião era o espaço mais distante do pedagógico stricto sensu. $\mathrm{O}$ morador da casa, geralmente, era alguém de confiança da direção do estabelecimento, sendo assim encarregado de cuidar do prédio nos períodos escolares e de não funcionamento das atividades letivas. $\mathrm{O}$ guardião também, muitas vezes, era o responsável pela abertura e fechamento geral do estabelecimento. 


\section{Considerações finais}

Durante seis anos ocorreu a construção do prédio oficial do Ginásio Estadual de Santo Antônio da Platina-PR, que foi inaugurado em 1953, e representava uma política educacional envolvendo o poder público estadual do Paraná e o governo Federal, em tempos de expansão do ensino secundário preconizado pelas reformas educacionais do Brasil dos anos de 1940. O prédio do ginásio platinense, que alterou a paisagem urbana da cidade, seguiu uma solução arquitetônica padrão aplicada em diferentes realidades paranaense e que sofria influência dos ideais escolanovistas.

A arquitetura do prédio e a distribuição dos espaços do Ginásio apresentaram, por meio da análise das plantas estruturais, três dimensóes. A primeira é a parte central do estabelecimento onde figurava o quadro de poder administrativo pedagógico, composto pelo gabinete da direção, sala de inspetores, secretaria, sala de professores, biblioteca, museu, gabinete médico, anfiteatro/saláo nobre. A segunda é formada pelas salas de aulas tradicionais e de aulas especiais (Trabalhos Manuais, Artes Industriais, Economia doméstica, Desenho, Educação Física/Esporte), onde a instrução de saberes/práticas e a aprendizagem formalizada eram praticadas de maneira sistematizada tendo o professor como sujeito de maior gradiente de poder. E, a terceira é constituída pelos espaços do jardim, pátio, quadra poliesportiva, refeitório/cantina, corredores, almoxarifado, lavanderia, casa do guardião, isto é, onde aconteciam relações que extrapolam as funções pedagógicas stricto sensu vivenciadas pelos sujeitos. As três dimensóes indicam que os espaços e seus usos podem variar conforme as relaçóes de aprendizagem, de poder e de sociabilidades vivenciadas pelos sujeitos no interior de uma cultura escolar. Da cultura escolar ginasial vivida nos espaços, esperava-se uma formação humanista, profissionalizante, nacionalista e preparatória para os próximos níveis de ensino.

Por fim, os espaços de uma cultura escolar representam um programa arquitetônico que se objetiva com lugares de escolarização. As edificações e o uso de seus espaços passam a contribuir para a elaboração de representaçóes sociais que vão sendo incorporadas pelos sujeitos da cultura escolar, bem como pelas famílias dos alunos e pelos moradores da cidade. As representações permitem reconhecer o edifício-escola como uma inovação que evidencia os sinais de ordem de uma dinâmica de poder educacional, cultural e político, em que as pessoas deveriam fazer parte como estruturantes, desse modo, integrando a noção de sociedade. 


\section{Referências}

ARAUjO, S. A. C. Professora Julia Wanderley, um mito na feminização do magistério paranaense (1874 - 1918). In: CONGRESSO BRASILEIRO DE HISTÓRIA DA EDUCAÇÃO. Sociedade Brasileira de História da Educação SBHE, 7., 2013, Cuiabá. Anais [...]. Cuiabá: UFMT, 2013. p. 1-14.

ARQUIVO do Ginásio Estadual de Santo Antônio da Platina. Colégio Estadual "Rio Branco": Álbuns de fotografias 1, 2.; Pasta com Plantas arquitetônicas do prédio; Livro Grades Escolares do Ginásio; Regimentos internos (1947; 1960; 1961).

BASTOS, M. H. C.; FARIA FILHO, L. M. (org.). A escola elementar no século XIX: o método monitorial / mútuo. Passo Fundo: Ediupf, 1999.

BENCOSTTA, M. L. A. Arquitetura e espaço escolar: reflexóes acerca do processo de implantação dos primeiros grupos escolares de Curitiba (1903-1928). Educar em revista, Curitiba, v. 17, n. 18, p. 103-141, 2001.

BENCOSTTA, M. L. A. (org.). História da educaçáo, arquitetura e espaço escolar. São Paulo: Cortez, 2005.

BRASIL. Decreto Lei no 4.244, de 09 de abril de 1942. Brasília, DF. Lei orgânica do ensino secundário.

CORREIA, A. P. P. Arquitetura Escolar: em busca da construção de escolas modernas no Paraná. In: CONGRESSO BRASILEIRO DE HISTÓRIA DA EDUCAÇÃO, 3., 2004, Curitiba. Anais [...]. Curitiba, 2004. p. 1-15.

CORREIA, A. P. P. Espaço escolar: o 'projeto-tipo' dos grupos escolares de Curitiba, na década de 1940. In: CONGRESSO LUSO-BRASILEIRO DE HISTÓRIA DA EDUCAÇÃO, 6., 2006, Uberlândia, 2006. p. 5457-5472.

COSTA, F. R. A história do Colégio Estadual "Rio Branco". 2001. Monografia (Graduação em História) - Universidade Estadual do Norte do Paraná, Jacarezinho-PR, 2001.

DALLABRIDA, N. A fabricaçáo escolar das elites: o ginásio catarinense na primeira república. Florianópolis: Cidade Futura, 2001.

ESCOLANO, A. Arquitetura como programa. Espaço-escola e currículo. In: VINÃO FRAGO, A.; ESCOLANO, A. (org.). Currículo, espaço e subjetividade: a arquitetura como programa. 2. ed. Rio de Janeiro; DP\&A, 2001. p. 19-58. 
FARIA FILHO, L. M.; VIDAL, D. G. Os tempos e os espaços escolares no processo de institucionalização da escola primária no Brasil. Revista Brasileira de Educaçáo, São Paulo, n. 14, p. 19-34, maio/ago. 2000.

FARIA FILHO, L. M.; GONÇALVES, I. A.; VIDAL, D. G.; PAULILO, A. L. A cultura escolar como categoria de análise e como campo de investigação na história da educação brasileira. Educaçáo e Pesquisa, São Paulo, v. 30, n. 1, p. 139-159, jan./abr. 2004.

HERNANDES, L. B. Cultura escolar no Norte Pioneiro do Paraná: o Ginásio Estadual de Santo Antônio da Platina-PR (1945-1960). 2019. 135 f. Dissertação (Mestrado em Educação) - Universidade Estadual de Londrina, Londrina, 2019.

HONORATO, T.; NERY, A. C. B. Constituição, agentes e usos de uma biblioteca de formação de professores (1897-1923). Revista Brasileira de História da Educaçáo, Maringá, v. 17, n. 2, n. 45, p. 175-207, abr./jun. 2017.

KINCHESCKI, A. P. S.; GASPAR DA SILVA, V. L.; VALLE, I. R. Materialidades educam? Representaçóes de professoras aposentadas de escolas públicas primárias (Santa Catarina, 1940-1970). Revista de Educaçáo Pública, Cuiabá, v. 26, n. 63, p. 857-875, set./dez., 2017.

MARTINS, M. R. Co-educaçáo, cultura escolar e seus limites: Ginásio Barão de Antonina (1942-1952). 2009. 99 f. Dissertação (Mestrado em Educação) Universidade do Estado de Santa Catarina, Florianópolis, 2009.

MAGALHÃES, J. P. Tecendo nexos: história das instituições educativas. Bragança Paulista: Ed. Universitária São Francisco, 2004.

MONARCHA, C. A Escola Normal da Praça: o lado noturno das luzes. São Paulo: Editora da Unicamp, 1999.

NORA, P. Entre memória e história: a problemática dos lugares. Projeto História. Sáo Paulo: n. 10, p. 7-28, dez. 1993.

PARANÁ. Governo do Estado. Mensagem apresentada à Assembleia Legislativa do Estado na abertura da sessáo legislativa de 1950, pelo senhor Moyses Lupion, governador do Paraná. Curitiba, 1950a.

PARANÁ. Governo do Estado. Relatório - Concretizaçáo do plano de obras do governador Moyses Lupion - 1947 a 1950. Curitiba, $1950 \mathrm{~b}$.

PARANÁ. Governo do Estado. Documento - Capacidade do Estabelecimento de 1961. Curitiba, 1961. 
ROCHA, H. H. P. A higienização dos costumes: a educação escolar e saúde no projeto do Instituto de Hygiene de Sáo Paulo (1918-1925). Campinas: Mercado de Letras. São Paulo: FAPESP, 2003.

SOUZA, R. F. Templos de civilizaçáo: a implantação da escola primária graduada no Estado de Sáo Paulo, 1890-1910. Sáo Paulo: Editora da Unesp, 1998.

SOUZA, R. F. Prefácio. In: BENCOSTTA, M. L. A. (org.). História da educaçáo, arquitetura e espaço escolar. São Paulo: Cortez, 2005. p. 7-13.

VIDAL, D. G. Escola Nova e processo educativo. In: LOPES, E. M. T.; FARIA FILHO, L. M.; VEIGA, C. G. (org.), 500 Anos de Educaçáo no Brasil. Belo Horizonte: Autêntica, 2000. p. 497-518.

VINÃO FRAGO, A.; ESCOLANO, A. (org.). Currículo, espaço e subjetividade: a arquitetura como programa. 2. ed. Rio de Janeiro: DP\&A, 2001.

VINÃO FRAGO, A. Historia de la educación y historia cultural: posibilidades, problemas, cuestiones. Revista Brasileira de Educaçáo, São Paulo, n. 0, p. 6382, set./dez. 1995.

. Espaços, usos e funçôes: a localização e disposição física da direção escolar na escola graduada. In: BENCOSTTA, M. L. A. (org.). História da educaçáo, arquitetura e espaço escolar. São Paulo: Cortez, 2005. p. 15-47. 